\title{
A cross-sectional study of inpatients with late stage of dementia in Southeast China and the associations between biochemical parameters and apolipoprotein E genotypes
}

This article was published in the following Dove Press journal:

Clinical Interventions in Aging

\author{
Bin Jiang ${ }^{1,2, *}$ \\ Xue-Ping Zhang,* \\ Mei-Fang Chen ${ }^{3}$ \\ Zheng Wang ${ }^{3}$ \\ Ming-Xue Zhao ${ }^{3}$ \\ Bin-Hua Chen ${ }^{3}$ \\ Hong-Lei $\mathrm{Li}^{\prime}$ \\ 'Department of Neurology and \\ Research Center of Neurology, \\ The Second Affiliated Hospital \\ of Zhejiang University School of \\ Medicine, Hangzhou, ${ }^{2}$ Department \\ of Neurology, The First Affiliated \\ Hospital of Xiamen University, \\ Xiamen, ${ }^{3}$ The Seventh People's \\ Hospital of Hangzhou, Mental Health \\ Center of Zhejiang University School \\ of Medicine, Hangzhou, People's \\ Republic of China \\ *These authors contributed equally \\ to this work
}

Correspondence: Hong-Lei Li

Department of Neurology and Research Center of Neurology, The Second

Affiliated Hospital of Zhejiang University

School of Medicine, No 88 Jiefang

Road, Hangzhou 31 0009, People's

Republic of China

$\mathrm{Tel}+8657 \mid 87784712$

Fax +86 57। 8778 47। I

Email lihonglei@zju.edu.cn

Bin-Hua Chen

The Seventh People's Hospital of Hangzhou, Mental Health Center of Zhejiang University School of Medicine, No 305 Tianmushan Road, Hangzhou 310013 , People's Republic of China

$\mathrm{Tel}+8657185126564$

Fax +86 57I 85I 2 46I3

Email chenbh1975@I26.com
Background: The purpose of this study was to analyze the disease distribution of patients in the late stage of dementia through a cross-sectional investigation and to clarify the association between apolipoprotein $\mathrm{E}(A P O E)$ genotypes and the serum levels of total cholesterol, total triglycerides, and blood glucose in the late-stage Alzheimer's disease (AD) patients.

Methods: Patients who were in the late stage of dementia in a mental health center were enrolled in this study. A broad battery of neuropsychological tests and neuroimaging was applied to make the diagnosis. The $A P O E$ genotype was determined by the multiplex amplification refractory mutation system polymerase chain reaction. The association between $A P O E$ genotype and the blood level of biochemical parameters was studied.

Results: A total of 155 patients were enrolled in this study. The majority of patients had AD $(67.8 \%)$, followed by vascular dementia (15.5\%), mixed dementia (9\%), and others $(7.7 \%)$. The $A P O E \varepsilon 4$ allele frequency was significantly different in the different groups. The serum level of total cholesterol (TC) in $A P O E \varepsilon 4$ carriers was higher than in non-carriers $(P<0.05)$. No statistically significant differences were found in the blood glucose and triglycerides (TG) levels between these two groups.

Conclusion: To our knowledge, this is the first paper to study the characteristics of late-stage dementia in hospital patients in Southeast China. We found that the disease distribution was quite consistent with previous prevalence studies. Moreover, we found that the serum level of TC was higher in APOE $\varepsilon 4$ carriers group. However, no association was found between the $A P O E \& 4$ allele and serum levels of glucose, TC and TG in the late stage of AD.

Keywords: Alzheimer's disease, $A P O E$, glucose, cholesterol, triglycerides

\section{Introduction}

Dementia is a broad battery of brain diseases that cause a long-term cognitive decline and is to affect a person's daily living. Alzheimer's disease (AD) is the most common cause of dementia, which is characterized by irreversible decline of memory and other cognitive domains. More than 44 million individuals are afflicted with AD nowadays, and the prevalence is expected to increase to 115.4 million by $2050 .{ }^{1}$ Many patients gradually lost the ability to work due to decline in cognitive abilities and finally lost the capability of physical self-maintenance in the late stage of the disease. In the People's Republic of China, many patients who are in the late stage of dementia are sent to mental disorder hospitals. In our opinion, these patients provide a very good resource to study the characteristics of dementia. However, there was no existing study about 
the late stage of dementia patients in the People's Republic of China. Therefore, one of our aims is to analyze the distribution of patients in the late stage of dementia through a cross-sectional investigation.

The apolipoprotein E ( $A P O E$ ) gene encodes a glycoprotein that plays an important role in central nervous system (CNS) lipid homeostasis during neuronal growth and in nerve regeneration. There are three major $A P O E$ isoforms: $A p o E \varepsilon 2$, $A p o E \varepsilon 3$ and $A p o E \varepsilon 4$. The $\varepsilon 4$ allele of $A P O E$ was believed to be a detrimental factor for sporadic Alzheimer's disease (SAD). ${ }^{2,3}$ It has been reported that the $\varepsilon 4$ allele is associated with a higher level of serum total cholesterol (TC) as well as with low-density lipoprotein cholesterol. ${ }^{4-6}$ Besides, previous studies also found that the $\varepsilon 4$ allele affected cerebral glucose metabolism and resulted in increased deposition of A $\beta .{ }^{7,8}$ However, most of these studies were performed in the Caucasian population with controversial results and there has been no study about the association between the APOE genotype and the levels of serum biochemical parameters in the late stage of dementia in AD patients. In the current study, we analyzed the proportion of $\mathrm{AD}$ among these dementia patients and studied the associations of $A P O E$ genotypes with the levels of TC, total triglycerides (TG) and the blood glucose of the AD patients.

\section{Methods and materials} Subjects

All the patients were enrolled at the Mental Health Center of Zhejiang University School of Medicine in Hangzhou from March 2014 to July 2016. The disease duration was more than 5 years (mean 10.26 years, standard deviation 3.974 years). The Diagnostic and Statistical Manual of Mental Disorders, 4th Edition, Text Revision (DSM-IV-TR) and National Institute of Neurological and Communicative Disorders and Stroke-Alzheimer's Disease and Related Disorders Association (NINCDS-ADRDA) criteria were applied to obtain the diagnosis of probable clinical AD. Moreover, the criterion ${ }^{9}$ for dementia with Lewy bodies (DLB), the criterion ${ }^{10}$ for frontotemporal dementia (FTD) and the NINDS-AIREN criteria for vascular dementia $(\mathrm{VaD})$ were applied to obtain the diagnosis of non-SAD forms of dementia. ${ }^{9-11}$ Furthermore, the routine medical examination, neurological examination, neuroimaging tests (CT or MRI), the Mini-Mental State Examination (MMSE), the Activity of Daily Living Scale (ADL) and the Clinical Dementia Rating (CDR) were applied to evaluate each participant. The exclusion criteria were described in our previous study. ${ }^{12}$ Briefly, patients with depression, mental retardation and other psychiatric disorders; hydrocephalus; syphilis; cognitive disorders caused by head trauma; poisoning; Huntington's disease; and severe heart, lung or kidney disease were excluded. This study was approved by the ethics committee of the Mental Health Center of Zhejiang University School of Medicine. All participants were Han people, and written informed consents were obtained from the patients or the guardians of the patients.

\section{Genotyping of APOE}

Genomic DNA was extracted from peripheral blood using a Blood Genomic DNA Extraction Kit(Tiangen, People's Republic of China). The primer for genotyping of $A P O E$ included Cys158/Arg158 (5'-ATGCCGATGACCTGCAGAATT3'/5'-ATGCCGATGACCTGCAGAATC-3'), Cys112/ $\operatorname{Arg} 112$ (5'-CGCGGACATGGAGGACGTTT-3')/(5'-CGC GGACATGGAGGACGTTC-3') and a common primer (5'-GTTCAGTGATTGTCGCTGGGCA-3'). The multiplex amplification refractory mutation system polymerase chain reaction was applied to determine $A P O E$ genotypes. ${ }^{13}$

\section{Measurement and analysis serum levels of TC and TG}

Serum TC, TG and fasting blood glucose levels were determined on the same auto-analyzer (Olympus, Tokyo, Japan, AU640). The serum TC level $>5.7 \mathrm{mmol} / \mathrm{L}$, TG level $>1.8 \mathrm{mmol} / \mathrm{L}$ and fasting blood glucose $>6.1 \mathrm{mmol} / \mathrm{L}$ were defined as hypercholesterolemia, hypertriglyceridemia and hyperglycemia, respectively.

\section{Statistical analysis}

The $A P O E \varepsilon 4$ allele frequency and $\varepsilon 4 \varepsilon 4$ genotype were compared using the chi-square test, and the age and the MMSE scores were assessed by one-way analysis of variance in the different groups. The mean value of glucose, TC and TG were assessed by independent-samples $t$-test in the different groups. Logistic regression analyses were performed to evaluate the possible associations between $A P O E$ genotype and the biochemical parameters. Covariates were age, history of hypertension and history of smoking and alcohol drinking. All statistical analyses were performed by the SPSS version 15.0 software (SPSS Inc., Chicago, IL, USA). $P$-values less than 0.05 were considered statistically significant.

\section{Results}

\section{The disease distribution and APOE genotype}

A total of 155 patients who were in the late stage of dementia were enrolled in this study. In our study cohort, the majority of the subjects were patients with $\mathrm{AD}$, which accounted for $67.8 \%$ of total subjects. In all, $15.5 \%$ and $9 \%$ of patients 
Table I Characteristics of subjects with different kinds of dementia

\begin{tabular}{|c|c|c|c|c|c|}
\hline Characteristics & AD & VaD & MD & $\begin{array}{l}\text { Other kinds } \\
\text { of dementia }\end{array}$ & $P$-value \\
\hline Number & 105 & 24 & 14 & 12 & \\
\hline Age (mean $\pm S D)$ (years) & $79.80 \pm 8.436$ & $79.12 \pm 11.403$ & $80.21 \pm 3.745$ & $75.33 \pm \mathrm{II} .484$ & NS \\
\hline Male/female & $32 / 73$ & $12 / 12$ & $5 / 9$ & $7 / 5$ & NS \\
\hline MMSE $($ mean $\pm S D)$ & $0.84 \pm 2.822$ & $3.08 \pm 6.086$ & $1.64 \pm 3.272$ & $8.08 \pm 9.030$ & $<0.05$ \\
\hline $\mathrm{ADL}($ mean $\pm \mathrm{SD})$ & $78.46 \pm 4.635$ & $78.50 \pm 4.065$ & $77.36 \pm 7.602$ & $73.42 \pm 9.239$ & NS \\
\hline $\mathrm{CDR}=3$ & 98 (93.33\%) & I8 (75.00\%) & $12(85.71 \%)$ & 7 (58.33\%) & $<0.05$ \\
\hline APOE $\varepsilon 4$ carrier & $65(61.90 \%)$ & 9 (37.50\%) & $6(42.86 \%)$ & $4(33.33 \%)$ & $<0.05$ \\
\hline APOE $\varepsilon 4 \varepsilon 4$ genotype & $20(19.04 \%)$ & $3(12.5 \%)$ & $0(0 \%)$ & I (8.33\%) & NS \\
\hline
\end{tabular}

Abbreviations: AD, Alzheimer's disease; VaD, vascular dementia; MD, mixed dementia; NS, non-significant; MMSE, Mini-Mental State Examination; ADL, Activity of Daily Living Scale; CDR, Clinical Dementia Rating; APOE, apolipoprotein E.

had $\mathrm{VaD}$ and mixed dementia, respectively. The remaining $7.7 \%$ consisted of subjects with FTD, DLB and patients who were very difficult to classify. The detailed disease distribution and $A P O E$ genotype are shown in Table 1. Age, sex, the ADL and the $\varepsilon 4 \varepsilon 4$ genotype did not have statistically significant differences. The MMSE scores, the CDR and the $A P O E \& 4$ allele frequency were significantly different in the different groups.

\section{Association between the serum levels of biochemical parameters and APOE genotypes in $A D$ patients}

The characteristics of $\mathrm{AD}$ patients with different $A P O E$ isoforms are shown in Table 2. The serum level of TC in $A P O E \& 4$ carriers was higher than in non-carriers. No statistically significant differences were found in the blood glucose and TG levels between these two groups. No correlations were found between the $A P O E \varepsilon 4$ carrier status and serum levels of glucose (adjusted odds radio 1.179, 95\% confidence interval $0.334-4.168, P=0.798$ ), TC (adjusted odds radio 2.028, 95\% confidence interval $0.392-10.502, P=0.400)$ and TG (adjusted odds radio $1.238,95 \%$ confidence interval $0.518-2.958, P=0.630)$. Details are shown in Table 3.

Table 2 Characteristics of AD patients with different APOE status

\begin{tabular}{llll}
\hline Characteristics & $\begin{array}{l}\text { Non-APOE } \\
\boldsymbol{\varepsilon} 4 \text { carrier }\end{array}$ & $\begin{array}{l}\text { APOE } \\
\boldsymbol{c} 4 \text { carrier }\end{array}$ & P-value \\
\hline Number & $40(38.1 \%)$ & $65(61.9 \%)$ & \\
Age, years & $79.55 \pm 8.676$ & $79.95 \pm 8.349$ & $\mathrm{NS}$ \\
Sex, male/female & $13 / 27$ & $19 / 46$ & $\mathrm{NS}$ \\
Fasting blood glucose, $\mathrm{mmol} / \mathrm{L}$ & $5.10 \pm 0.79$ & $5.18 \pm 0.97$ & $\mathrm{NS}$ \\
Serum triglycerides, $\mathrm{mmol} / \mathrm{L}$ & $\mathrm{I} .69 \pm 0.57$ & $1.96 \pm \mathrm{I} .03$ & $\mathrm{NS}$ \\
Total cholesterol, mmol/L & $4.21 \pm 0.94$ & $4.62 \pm \mathrm{I} .0 \mathrm{I}$ & $\mathrm{P}=0.037$ \\
Hypertension & 27 & 40 & $\mathrm{NS}$ \\
Alcohol users $(>\mathrm{I}$ drink/week) & 4 & 7 & $\mathrm{NS}$ \\
Cigarette smoking & 4 & 6 & $\mathrm{NS}$ \\
\hline
\end{tabular}

Notes: APOE genotypes: $\varepsilon 2 / 2$ or $\varepsilon 2 / 3$ or $\varepsilon 3 / 3$ (non-APOE $\varepsilon 4$ carrier); $\varepsilon 2 / 4, \varepsilon 3 / 4$, or $\varepsilon 4 / 4$ (APOE $\varepsilon 4$ carrier).

Abbreviations: AD, Alzheimer's disease; APOE, apolipoprotein E; NS, non-significant.

\section{Discussion}

With the increase in human lifespan, the age-related neurodegenerative diseases have become the biggest challenges of the 21 st century. Dementia, including AD, is one of the most devastating neurodegenerative disorders that affect millions of people annually. In the People's Republic of China, many late-stage dementia patients are sent to mental disorder hospitals due to loss of ability of physical self-maintenance and mental confusion. In this study, we analyzed the disease distribution of patients who were in the late stage of dementia in a mental disorder hospital in Southeast China. We found that the most common type of dementia was AD (67.8\%), followed by $\mathrm{VaD}(15.5 \%)$ and mixed dementia (9\%), while FTD and DLB were comparatively rare in our study cohort. These results were quite consistent with previous studies. For example, researchers studied the disease distribution of 1,194 cases of dementia in patients aged above 70 years in Spanish populations and found that 707 (59.2\%) had AD and 238 (19.9\%) had VaD. ${ }^{14}$ Besides, in Italy, a prevalence study of dementia in an elderly rural population found that AD accounted for $64 \%, \mathrm{VaD}$ for $27 \%$ and other dementia diseases for $9 \% .{ }^{15}$ Moreover, in a meta-analysis of prevalence of dementia in developing countries, $\mathrm{AD}$ was reported to account for $60 \%$, whereas $\mathrm{VaD}$ accounted for about $30 \%{ }^{16}$ Although these were all results from prevalence studies and our study was a cross-sectional study of inpatients of latestage dementia, the results were comparable. As a result, we

Table 3 Effects of APOE \&4 allele on biochemical parameters

\begin{tabular}{llll}
\hline $\begin{array}{l}\text { Biochemical } \\
\text { parameters }\end{array}$ & OR & $\mathbf{9 5 \%} \mathbf{C l}$ & $P$-value \\
\hline Blood glucose & 1.179 & $0.334-4.168$ & 0.798 \\
Total cholesterol & 2.028 & $0.392-10.502$ & 0.400 \\
Total triglycerides & 1.238 & $0.518-2.958$ & 0.630 \\
\hline
\end{tabular}

Note: Logistic regression model was adjusted for age, history of hypertension, alcohol use and smoking use.

Abbreviations: $A P O E$, apolipoprotein $\mathrm{E}$; OR, odds ratio; $\mathrm{Cl}$, confidence interval. 
postulate that inpatients in the late stage of dementia are a small focus group of these disease groups, which makes it a good resource for investigating this disorder.

In our study results, the $A P O E \varepsilon 4$ allele frequency differed significantly between the four subgroups, which was consistent with previous studies in Chinese AD patients. ${ }^{17}$ The $A P O E$ protein is believed to play an important role in CNS lipid homeostasis during neuronal growth and in nerve regeneration. Recently, one study indicated that a higher serum level of total cholesterol was associated with $A P O E \& 4$ carriers in a cognitively normal aging population. ${ }^{18}$ Previous studies reported the $A P O E \varepsilon 4$ status had an influence on the level of low-density lipoprotein cholesterol and high-density lipoprotein cholesterol. ${ }^{19}$ In our study, the serum level of TC was higher in the APOE $\varepsilon 4$ carriers, compared with the non- $A P O E \varepsilon 4$ carrier group. This result suggested that the $A P O E$ protein might be involved in a specific pathophysiologic mechanism of lipid metabolism in the development of AD.

Lately, it has been reported that dysregulation of glucose metabolism in the brain is a risk factor for mild cognitive impairment and AD. ${ }^{20,21}$ Besides, one study suggested that high serum glucose levels may worsen cognitive function as well as accelerate the cognitive decline. ${ }^{22}$ Some studies reported that $A P O E \varepsilon 4$ modulates regional cerebral glucose metabolism and affects the signal of glucose and amyloid metabolic pathways in the pathogenesis of AD. ${ }^{23,24}$ Another research indicated that the mean prevalence of PET amyloid positivity is $95 \%$ in $A P O E$ \&4-positive AD patients. ${ }^{25}$ In addition, previous studies have reported that the $A P O E$ $\varepsilon 3$ genotype had higher glucose levels than the $A P O E$ $\varepsilon 4$ genotype. ${ }^{26}$ Furthermore, APOE $\varepsilon 4$ carrier status and elevated blood glucose were associated with more severe AD pathology. ${ }^{27}$ Overall, all these studies have demonstrated that the $A P O E$ protein plays an important role in the pathogenesis of late-onset $\mathrm{AD}$, not only in the aspect of $A \beta$ deposition but also in the aspect of cerebral glucose metabolism. However, in our study, we were unable to find a positive association between the level of blood glucose and $A P O E$ genotypes.

There are some limitations of our study. First and most important of all, the sample size was comparatively small. It will be necessary to replicate these study results in a large population. Besides, we have only analyzed some basic biochemical parameters in this current study. A further extension of these parameters, for example, the level of glucose intolerance and insulin resistance, will be more accurate and powerful.

\section{Conclusion}

To the best of our knowledge, this is the first paper to study the characteristics of late-stage dementia in hospital patients in Southeast China. We found that the disease distribution was quite consistent with previous prevalence studies. Moreover, we found that the serum level of TC was higher in the $A P O E \& 4$ carrier group. However, no association was found between the APOE $\varepsilon 4$ allele and serum levels of glucose, TC and TG in the late stage of AD.

\section{Acknowledgment}

This work was supported by grants from the National Natural Science Foundation (81500908).

\section{Disclosure}

The authors report no conflicts of interest in this work.

\section{References}

1. Wimo A, Jönsson L, Bond J, Prince M, Winblad B; Alzheimer Disease International. The worldwide economic impact of dementia 2010. Alzheimers Dement. 2013;9(1):1-11.e13.

2. Saunders AM, Strittmatter WJ, Schmechel D, et al. Association of apolipoprotein E allele epsilon 4 with late-onset familial and sporadic Alzheimer's disease. Neurology. 1993;43(8):1467-1472.

3. Pericak-Vance MA, Bebout JL, Gaskell PC Jr, et al. Linkage studies in familial Alzheimer disease: evidence for chromosome 19 linkage. Am J Hum Genet. 1991;48(6):1034-1050.

4. Liu HC, Hong CJ, Wang SJ, et al. ApoE genotype in relation to $\mathrm{AD}$ and cholesterol: a study of 2,326 Chinese adults. Neurology. 1999;53(5): 962-966.

5. Lückhoff HK, Kidd M, van Rensburg SJ, van Velden DP, Kotze MJ. Apolipoprotein E genotyping and questionnaire-based assessment of lifestyle risk factors in dyslipidemic patients with a family history of Alzheimer's disease: test development for clinical application. Metab Brain Dis. 2016;31(1):213-224.

6. Tanzi RE. The genetics of Alzheimer disease. Cold Spring Harb Perspect Med. 2012;2(10). pii: a006296.

7. Patil SP, Ballard R, Sanchez S, Osborn J, Santangelo D Jr. ApoE: the link between Alzheimer's-related glucose hypometabolism and Abeta deposition? Med Hypotheses. 2012;78(4):494-496.

8. Ossenkoppele R, van der Flier WM, Zwan MD, et al. Differential effect of APOE genotype on amyloid load and glucose metabolism in AD dementia. Neurology. 2013;80(4):359-365.

9. McKeith IG, Dickson DW, Lowe J, et al; Consortium on DLB. Diagnosis and management of dementia with Lewy bodies: third report of the DLB Consortium. Neurology. 2005;65(12):1863-1872.

10. Rascovsky K, Hodges JR, Knopman D, et al. Sensitivity of revised diagnostic criteria for the behavioural variant of frontotemporal dementia. Brain. 2011;134(Pt 9):2456-2477.

11. Roman GC, Tatemichi TK, Erkinjuntti T, et al. Vascular dementia: diagnostic criteria for research studies. Report of the NINDS-AIREN International Workshop. Neurology. 1993;43(2):250-260.

12. Li HL, Shi SS, Guo QH, et al. PICALM and CR1 variants are not associated with sporadic Alzheimer's disease in Chinese patients. J Alzheimers Dis. 2011;25(1):111-117.

13. Donohoe GG, Salomaki A, Lehtimaki T, Pulkki K, Kairisto V. Rapid identification of apolipoprotein $\mathrm{E}$ genotypes by multiplex amplification refractory mutation system PCR and capillary gel electrophoresis. Clin Chem. 1999;45(1):143-146. 
14. de Pedro-Cuesta J, Virués-Ortega J, Vega S, et al. Prevalence of dementia and major dementia subtypes in Spanish populations: a reanalysis of dementia prevalence surveys, 1990-2008. BMC Neurol. 2009;9:55.

15. Prencipe M, Casini AR, Ferretti C, Lattanzio MT, Fiorelli M, Culasso F. Prevalence of dementia in an elderly rural population: effects of age, sex, and education. J Neurol Neurosurg Psychiatry. 1996;60(6):628-633.

16. Kalaria RN, Maestre GE, Arizaga R, et al; World Federation of Neurology Dementia Research Group. Alzheimer's disease and vascular dementia in developing countries: prevalence, management, and risk factors. Lancet Neurol. 2008;7(9):812-826.

17. Li HL, Yang P, Liu ZJ, et al. Common variants at Bin1 are associated with sporadic Alzheimer's disease in the Han Chinese population. Psychiatr Genet. 2015;25(1):21-25.

18. Tao QQ, Chen Y, Liu ZJ, et al. Associations between apolipoprotein E genotypes and serum levels of glucose, cholesterol, and triglycerides in a cognitively normal aging Han Chinese population. Clin Interv Aging. 2014;9:1063-1067.

19. Raygani AV, Rahimi Z, Kharazi H, Tavilani H, Pourmotabbed T. Association between apolipoprotein E polymorphism and serum lipid and apolipoprotein levels with Alzheimer's disease. Neurosci Lett. 2006; 408(1):68-72.

20. Chen Z, Zhong C. Decoding Alzheimer's disease from perturbed cerebral glucose metabolism: implications for diagnostic and therapeutic strategies. Prog Neurobiol. 2013;108:21-43.
21. Crichton GE, Elias MF, Buckley JD, Murphy KJ, Bryan J, Frisardi V. Metabolic syndrome, cognitive performance, and dementia. J Alzheimers Dis. 2012;30 Suppl 2:S77-S87.

22. Kerti L, Witte AV, Winkler A, Grittner U, Rujescu D, Flöel A. Higher glucose levels associated with lower memory and reduced hippocampal microstructure. Neurology. 2013;81(20):1746-1752.

23. Keeney JT, Ibrahimi S, Zhao L. Human ApoE isoforms differentially modulate glucose and amyloid metabolic pathways in female brain: evidence of the mechanism of neuroprotection by ApoE2 and implications for Alzheimer's disease prevention and early intervention. J Alzheimers Dis. 2015;48(2):411-424.

24. Seo EH, Kim SH, Park SH, Kang SH, Choo IH. Alzheimer's Disease Neuroimaging Initiative. Topographical APOE $\varepsilon 4$ genotype influence on cerebral metabolism in the continuum of Alzheimer's disease: amyloid burden adjusted analysis. J Alzheimers Dis. 2016;54(2):559-568.

25. Ba M, Kong M, Li X, Ng KP, Rosa-Neto P, Gauthier S. Is ApoE $\varepsilon 4$ a good biomarker for amyloid pathology in late onset Alzheimer's disease? Transl Neurodegener. 2016;5:20.

26. Larson IA, Ordovas JM, DeLuca C, Barnard JR, Feussner G, Schaefer EJ. Association of apolipoprotein (Apo)E genotype with plasma apo E levels. Atherosclerosis. 2000;148(2):327-335.

27. Bangen KJ, Himali JJ, Beiser AS, et al. Interaction between midlife blood glucose and APOE genotype predicts later Alzheimer's disease pathology. J Alzheimers Dis. 2016;53(4):1553-1562.
Clinical Interventions in Aging

\section{Publish your work in this journal}

Clinical Interventions in Aging is an international, peer-reviewed journal focusing on evidence-based reports on the value or lack thereof of treatments intended to prevent or delay the onset of maladaptive correlates of aging in human beings. This journal is indexed on PubMed Central, MedLine,

\section{Dovepress}

CAS, Scopus and the Elsevier Bibliographic databases. The manuscript management system is completely online and includes a very quick and fair peer-review system, which is all easy to use. Visit http://www.dovepress. $\mathrm{com} /$ testimonials.php to read real quotes from published authors. 